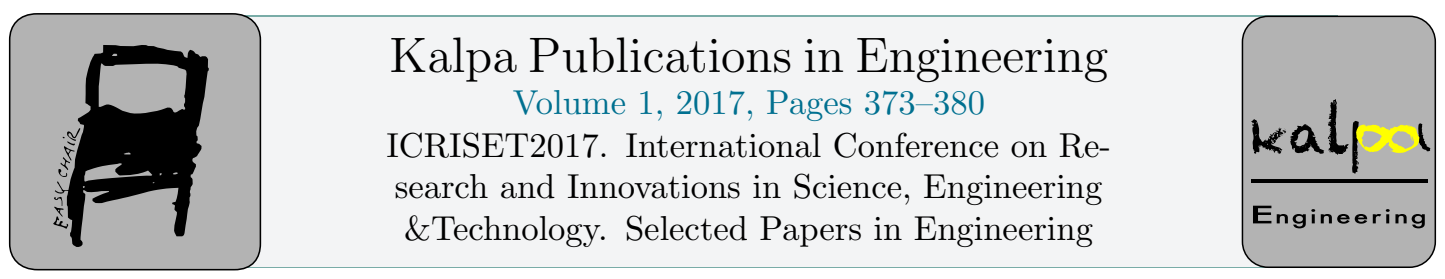

\title{
Robo Control by Brain Signal
}

\author{
Parul.H.Panchal $^{1}$,Nirav Kalathiya ${ }^{2}$, Bhavin Nandavana $^{3}$,Janki Panchal ${ }^{4}$ \\ ${ }^{1}$ Assistance Professor, Electronics Department, BVM Engineering College, Gujarat \\ ${ }^{2,3,4}$ BE Final Year Students, Electronics Department, BVM Engineering College, Gujarat \\ phpanchal@bvmengineering.ac.in, nirav.kalathiya9@gmail.com, \\ bhavinnandavana91@ymail.com, jankipanchal5@gmail.com
}

\begin{abstract}
This research paper presents to develop a bio-signal acquisition system and rehabilitation technique based on "Cognitive Science application of robot controlled by brain signal". We are trying to Developing a data acquisition system for acquiring EEG signals from Brain sense head band and also designing new algorithm for detecting attention and meditation wave and implementing on Robotics platform By using Embedded core.[1]
\end{abstract}

Keywords- Brain sense Head band, EEG Robotic Car

\section{Introduction}

Cognitive science is synchronization between Brain computer interfacing (BCI) technology and Human brain signal. Our society sufferers from many neurological disorders, at that time we have only source of BIO-SIGNAL. Rehabilitation Devices are used for acquiring Bio signal. EEG signals are in very Low range and Rehabilitation Devices amplifying that signals and translating EEG signals to digital pack of data, which can be given to embedded core. In embedded core, we are trying to develop one algorithm program accordingly different set of EEG Value like meditation, attention etc. So, BCI technology is various broad areas for Cognitive science applications. ${ }^{[1]}$

\section{A. Introduction of Electronics Module}

"BRAIN SENSE HEADBAND" is rehabilitation Devices for acquiring EEG Signal. In built purification of the signal which produced by brain. Brain signal are in analog form, using A/D converter it converts in digital signals then low noise amplifier and filter the signals are automatically process done by itself in machine. Finally we getting output of the signals are so pure means the signals are not noisy. The machine have electrode for detecting the mind signal. 
"ATMEGA328" is use as our embedded core in project. Our target is to send motion command to Arduino from brain sense headband .Brain sense measures directly EEG Signal values by using measurement techniques of electrodes. Accordingly different type value of attention and meditation wave, we have to design algorithm for controlling robot motion direction which based on our embedded core. ${ }^{[2]}$

\section{BASIC BLOCK DIAGRAM / PRINCIPLE}

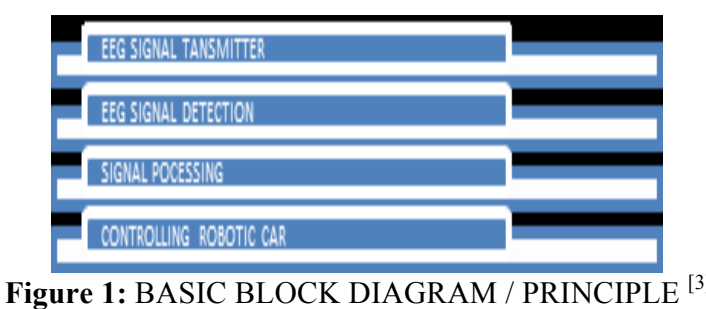

BCI technology is used for synchronization between EEG sensor and computer. EEG sensor like Brain sense headband use for acquiring EEG signal. We were getting the EEG signal from brain sense head band by using measurement techniques of electrode. Electrodes measuring EEG values and converting this signal into digital signal via A/D converter. After converting digital signal, it must be required to amplifying that signal because we getting very low range value in term of microvolt. So we must be needed amplifying them and stored it. This whole process done by inside the brain sense headband.

Once we getting signal from Brain sense, we have to check practically .for that we are using Mind wave reading software. Mind wave reading is common platform for getting EEG reading value. But before that we have to connect our EEG Sensor with computer via Bluetooth. Because each and every second data will transmitted by EEG Sensor so at the different time we have a different value of EEG this whole process is signal processing of EEG. Another technique of getting signal value by done with MATLAB GUI.

Once we stored EEG Packed data then we need to be transmitting this data into embedded core. Because EEG sensor data directly converted into motion data by using an embedded core. As per designing of algorithm, our project will run. ${ }^{[5]}$ Design algorithm will show in next part. 


\section{DESIGN ALGORITHM}

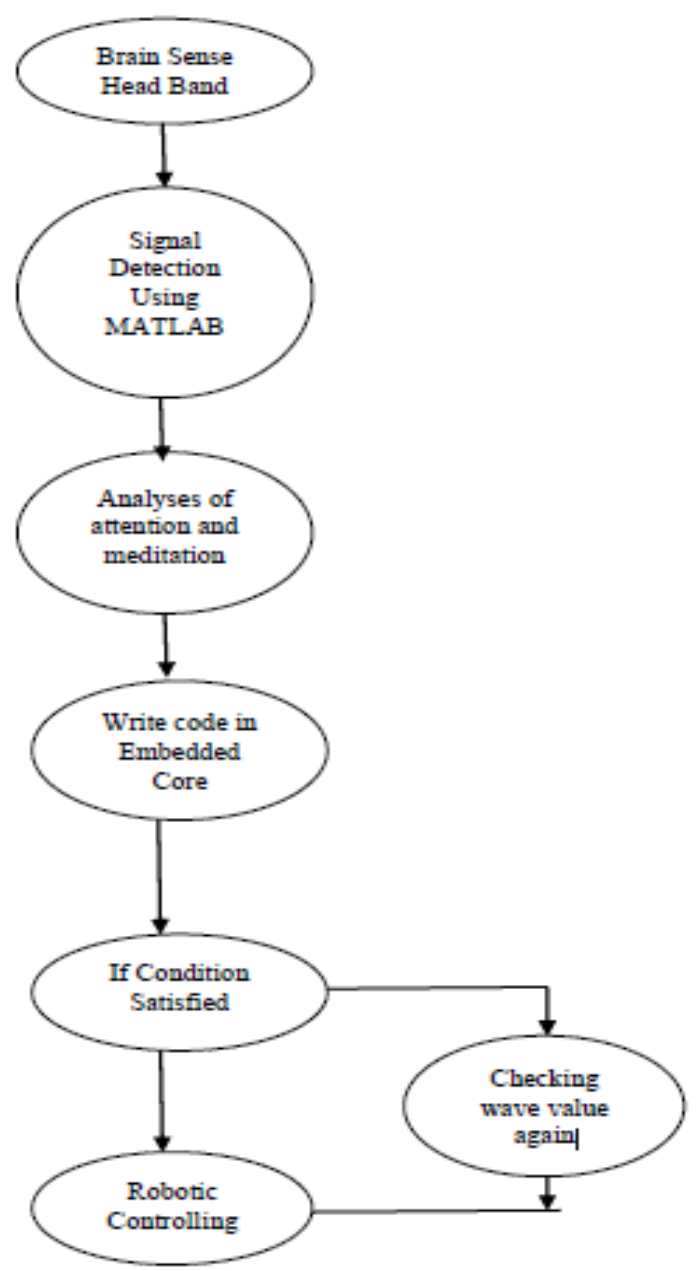

Figure 2: FLOW CHART

\section{METHODOLOGY OF DETECTING EEG SIGNAL}

There are different types of machine for record the EEG signal which are Neurosky, Emotive, Brain sense etc. In built purification of the signal which produced by brain. Brain signal are in analog form, using A/D converter it converts in digital signals then low noise amplifier and filter the signals then the output of the signals are so pure means the signals are not noisy. The machine have electrode for detecting the mind signal. ${ }^{[3]}$ 


\section{A. Brain Sense Head Band Specifications}

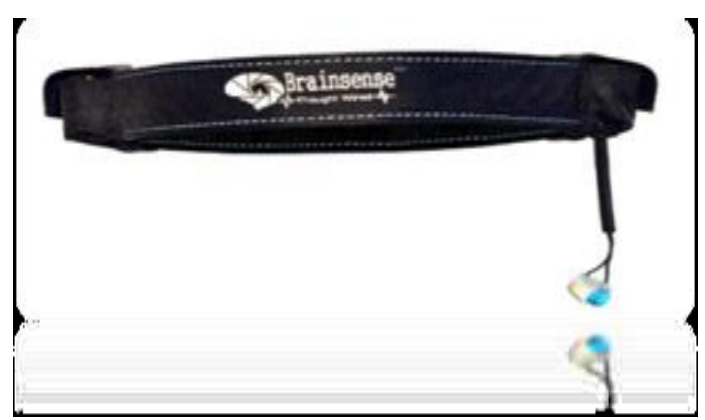

Figure 3: BRAIN SENSE HEADBAND

It is measure the electrical activity of our mind and eye blinks and transmits digital data via Bluetooth. It consists of a headset, an ear-clip and a sensor arm.

\begin{tabular}{|l|l|}
\hline Part & $\begin{array}{l}\text { TGAM1 module, Dry } \\
\text { Electrode, Ear clip } \\
\text { electrode }\end{array}$ \\
\hline Connection & $\begin{array}{l}\text { Automatic Bluetooth } \\
\text { wireless pairing }\end{array}$ \\
\hline Power & 6 hours battery run time \\
\hline Bluetooth & $\begin{array}{l}\text { Bluetooth v2.1 Class 2 (10 } \\
\text { meters range) }\end{array}$ \\
\hline System & iOS and Android support \\
\hline
\end{tabular}

Table 1: SPECIFICATIONS

\section{B. Robotic Module Specification}

Brain sense Headband measures the electrical activities of neuron. it will transmit the data of attention and meditation value. Each people having different- different meditation value and it will detect by Bluetooth module which will be available in robotic car. It will sense the meditation threshold value which will be already defined in program. If Bluetooth module sense the upper limit of threshold value than Robotic car moves in forward direction.

\section{Bluetooth Transceiver Module with TTL Output-HC05}

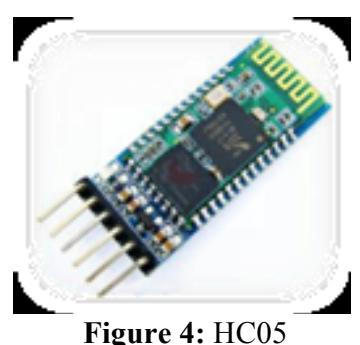

Figure 4: $\mathrm{HC} 05$

It is Transceiver module which is used for transmitting and receiving digital data as UART232 serial communication from EEG brain sense headband. We also connect this Bluetooth module with our embedded core. It will directly getting attention and meditation value from Headband. 


\section{Motor Driver IC L293D}

L293D is motor driver IC which will be use for synchronizing Arduino output to motor available in our robotic car. Two motors are used in our car. Output of arduino is 3.3 volt. and motor will work in 12 volt. So, we must have standard IC which will control the arduino outputs and gives 12 volt to motor. So our robotic car will move.

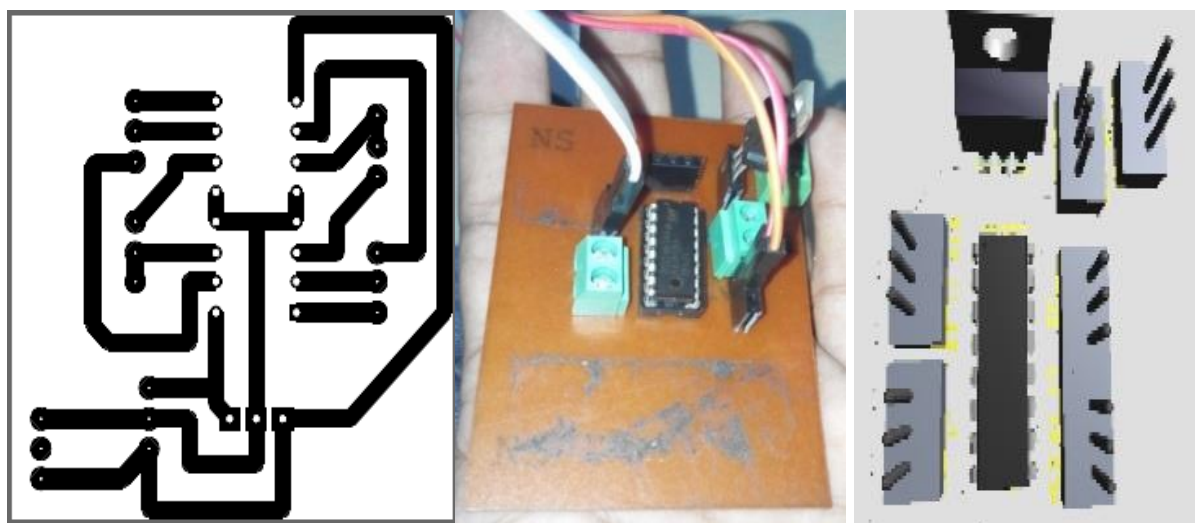

Figure 5: PCB LAYOUT, CIRCUIT OF L293D, 3D LAYOUT

\section{E. Working of Bluetooth}

HC-06 is able to work in slave mode at the Brain sense headband.HC05 is able to work in master and slave mode at the Robotic Car side. We have set the HC05 in master mode and HC06 in slave mode.so it will connect automatically and transmitting data from Brain sense headband and receiving data in Robotic Car Module.

\section{ANALYSES OF ATTENTION \& MEDITATION SIGNAL VALUE}

Attention and meditation will debugging by brain sense head band while connect with the computer. In software Implementation we will focus on our EEG Signal acquiring techniques from Brain sense head band Attention and Meditation value of different people is depending on concentration of eye strength. ${ }^{[5]}$

\section{A. Experimental Data}

In our program we mentioned the threshold value of meditation value .threshold value span is between to 1 to $100 \mathrm{mv}$.Nomally we will take $10,20,30,40 \ldots . .100$ threshold value. For experimental data we will take $40 \mathrm{mv}$ meditation value as a threshold and testing on 2 different people.Threshold value already mentioned in our program. We will get result by changing threshold value one by one in program and testing the output on robotic car whether car will starts or not. 


\begin{tabular}{|l|l|l|}
\hline People & $\begin{array}{l}\text { Threshold } \\
\text { value }\end{array}$ & $\begin{array}{l}\text { Robot } \\
\text { Movement }\end{array}$ \\
\hline Bhavin & 40 & Forward \\
\hline Bhavin & 30 & Forward \\
\hline Bhavin & 10 & Forward \\
\hline Nirav & 10 & Forward \\
\hline Nirav & $30,40,50$ & NA \\
\hline
\end{tabular}

Table 2: EXPERIMENT DATA
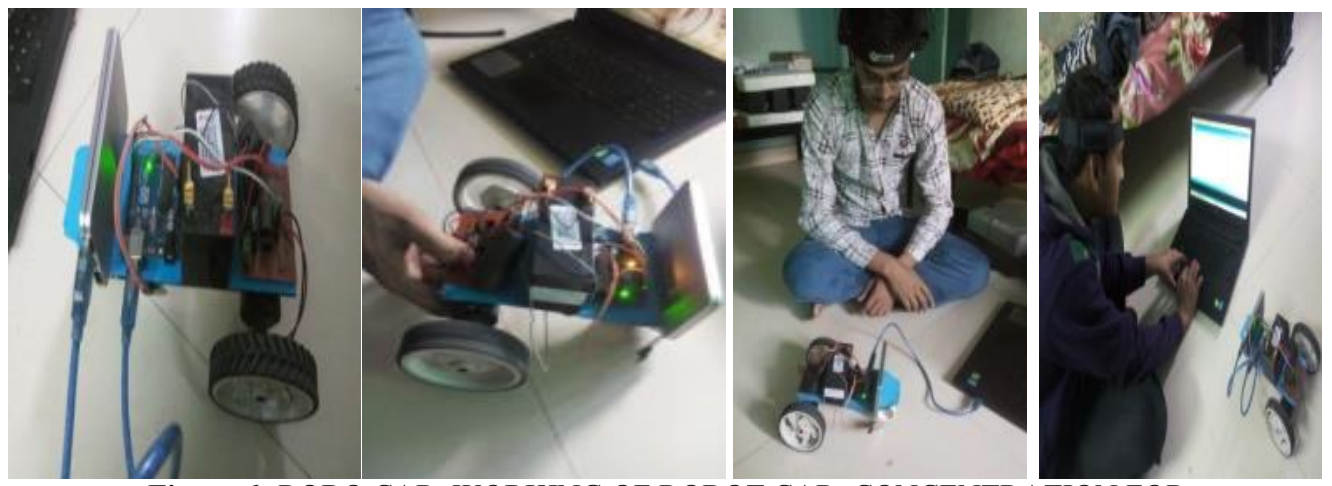

Figure 6: ROBO CAR, WORKING OF ROBOT CAR, CONCENTRATION FOR

\section{B. Proposed Output}

Our main target is to move robot on each direction. By using EEG Brain sense Headband robot will able to move in forward direction. By using android app (touch joystick) we will control the entire robotic car.

\section{ANDROID APP DEVELOPMENT}

Firstly we will try to develop android app based on buttons (left,right,forward,reverse).MIT INVENTORE is online android application tool which will be using to develop our primary app.

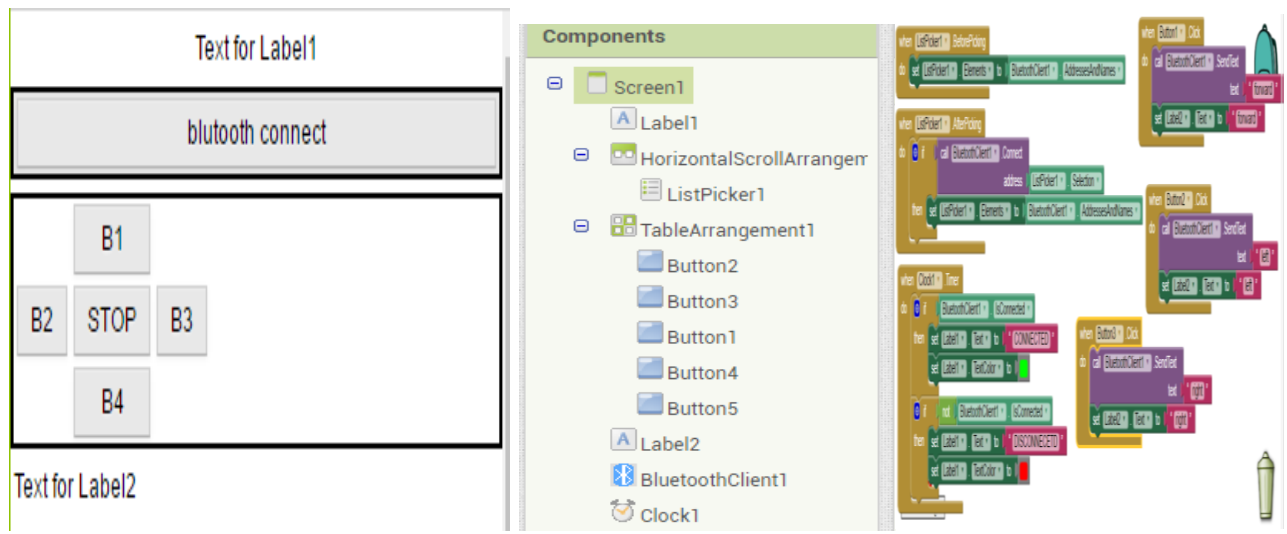

Figure 7: DESIGNER PART IN MIT INVENTOR, BLOCK PART IN MIT INVENTOR 


\section{CONCLUSION}

Robotic car will move in each direction (left,right,forward,reverse) when it receiving command from android app.Brain sense head band are used for acquiring Bio signal. EEG signals are in very Low range and Rehabilitation Devices amplifying that signals and translating EEG signals to digital pack of data which can be given to embedded core. In embedded core we are trying to develop one algorithm program accordingly different set of EEG Value like meditation, attention etc.

\section{OUTPUT \& FUTURE DIRECTION}

Robotic car moves in forward direction as Bluetooth module getting the threshold value of meditation value and robo will moves in each direction by help of android app.

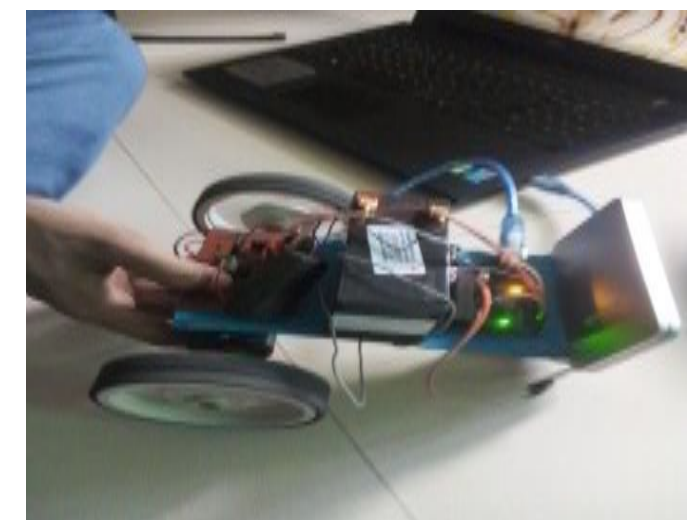

Figure 8: ROBOT MOVES IN FORWARD DIRECTION

\section{ACKNOWLEDGMENT}

At the outset, we take the opportunity to express out deep gratitude to a few individuals who guided us in every aspect of our project. We are deeply grateful to our internal guide Prof. Parul $\mathrm{H}$. Panchal for her continuous guidance and motivation to complete the assigned work as per required and motivation to innovate the project. She showed us the correct way to approach our project work. Without her experience and knowledge, it would have been very difficult to do quality work in the given time. We are also grateful to Dr. T. D. Pawar (Head of Electronics Department) for suggesting us some modification and innovative approach in our proposed project. We would like to take this opportunity to thankful to Dr. D. L. Vala (Project Coordinator) for his guidance and constant support during the entire project term. 


\section{REFERENCES}

[1] International Journal Advanced Research engineering in Electrical, Electronicsand Instrumentation Engineering.Siliveru Ramesh , K.Harikrishna J.Krishna Chaitanya (An ISO 3297: 2007 Certified OrganizationVol. 3, Issue 8, August 2014) Brainwave Controlled Robot Using Bluetooth

[2] IEEETransactions On Human-Machine Systems, Vol. 43, No. 2, March 2013161 EEGBased Brain-Controlled Mobile Robots: A Survey Luzheng Bi, Member, Ieee, Xin-An Fan, And Yili Liu, Member, Ieee

[3] IOSR Journal of Electronics and Communication Engineering. Devashish Salvekar, Amrita Nair , Dany Bright , Prof.S.A.Bhisikar (IOSR-JECE) e-ISSN: 2278-2834,p- ISSN: 22788735. PP 36-44 Innovation in engineering science and technology NCIEST-2015( JSPM'S Rajarshi Shahu College Of Engineering,Pune-33,Maharashtra ,India) Mind Controlled Robotic Arm

[4] Lavanya Thunuguntla et al Int. Journal of Engineering Research and Applications. Lavanya Thunuguntla, R Naveen Venkatesh Mohan, P Mounika ( ISSN : 2248-9622, Vol. 4, Issue 4( Version 1), April 2014, pp.195-198)Reserch article on EEG Based Brain Controlled Robot

[5] International Journal of Innovative and Emerging Research . R.S.Shekhawat1a, Rajat Sharma and Ravi Rao (Engineering Volume 3, Issue 3, 2016) Brain Controlled Robot Car. 